\title{
Color separation Algorithm and Rice identification
}

- Phan Huynh Lam

- Nguyen Thanh Nam

- Pham Van Duy

- Nguyen Thien Binh

- Le Thanh Son

DCSELAB, University of Technology, VNU-HCM

(Manuscript Received on December 11 $1^{\text {th }}, 2013$; Manuscript Revised August 26 $6^{\text {th }}$, 2014)

\section{ABSTRACT:}

This article presents a method to identify good and bad grain and then they will be classified and processed. The algorithm mentioned here will determine the good and bad grain at high speed frame (18500 frames/s), and determine the speed of rice moving. The identification of better or worse than the threshold used in

Keywords: CCD Line, rice sorting, OpenCV.

\section{INTRODUCTION}

Rice color separating is the high speed image processing system (frame> 1000 frames / s), it is able to classify many types different colors of rice (white, yellow, crimson...) to determine the best kind of rice that is pure white.

For identifying accurately and promptly, we use the CCD line camera system has rate up to 18500 frame / s [1] with a reference appropriate wavelength. We tested the layout system such as Figure 1. One axis will move with high speed to symbolize the movement of grain, the inspectorial cameras are installed on the vertical axis. We the algorithm are combination of light wavelengths and identify appropriate length of grain. This paper describes the experimental results: the influence of the light wavelength, the effect of imagecapturing speed, identity technique and threshold filtering.

conducted experiments with different types of light (White LED, Halogen, Fluorescence, Blue ...).

Substantial work for classifying and identifying varieties of grain has been reported. B.S. Anami et al., [2] described a method for gradation and classification of different grain such as wheat, Bengal gram, groundnut, etc. An artificial neural network approach is used in the Identification and classification of the bulk grain samples by N.S. Visen et.al, [3]. Harlick, et.al., [4] has presented a paper on classification of image using textural features. This work is done 
based on gray-tone spatial dependencies for easily computable textural features. LIU zhaoyan et al., [5] projected his ideas on Identification of different varieties of rice grain using neural network and image processing. They used an algorithm of digital image based on morphological and color features of different rice varieties. By using image analysis techniques, M.A. Shahin and S.J. Symons [6] automated the manual sieving procedure. Using flatbed scanner, J.Paliwal et al., [7] performed a research for both bulk and single seed images. N.S. Visen et al., [3] developed and optimized a technique by extracting the morphological, texture, and color features using image of single grain for discriminating various types of grain. Identifying the food grain and evaluating its quality using pattern classification is done by Sanjivani Shantaiyai, et al., [8]. H. Rautio and O.Silvn [9] carried out experiment to determine the average grain size and classified using morphology and texture features. This paper presents resorting rice using the technique Image Processing and Optical.

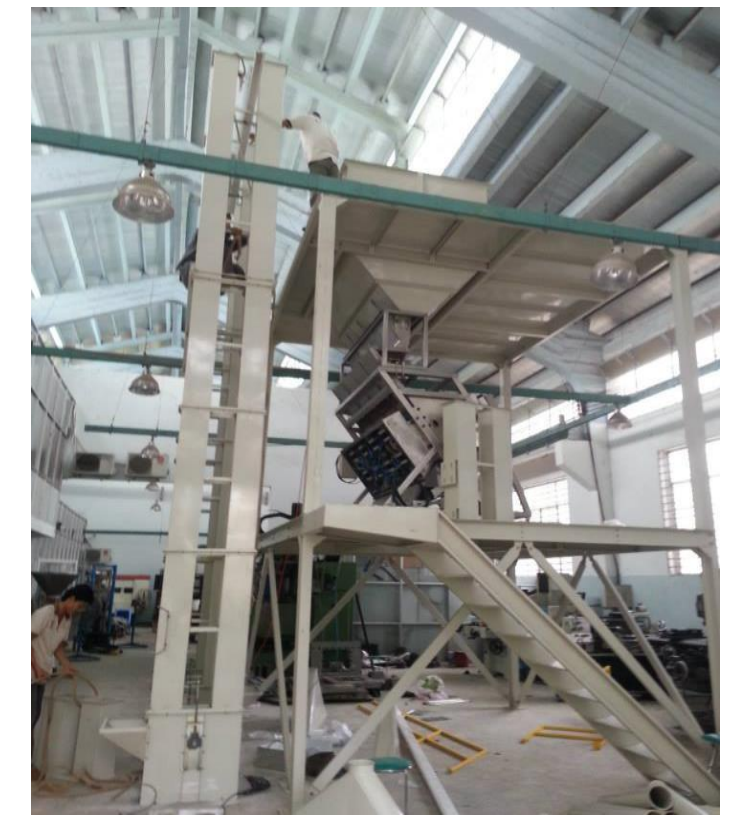

Figure 1. Rice checking and identifying system

\section{RECOGNITION ALGORITHM}

For detecting errors rice, we will split each rice type with their suitable thresholds. Here, we will use the light with appropriate wavelength to project to the rice and increase the resonance effects on them such as the following figure:

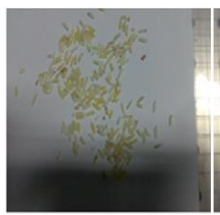

Rice without lighting

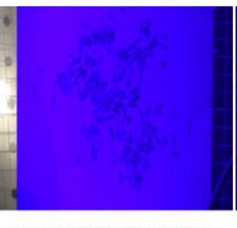

Rice is lighted with blue LED

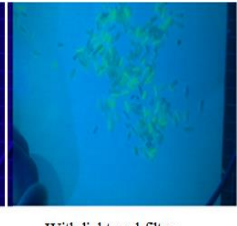

With light and fiter
Figure 2. The impact of the light to the bad and good rice

When we use a suitable light wavelength to impact to the rice, we will get the bad rice very clearly because it reflects the light and has the color that is like red or yellow. This helps to increase the identifying ability and by the highlevel filtering obtained results, $99.8 \%$ bad rice is filtered out (obtained results from 10 experiments, 
200 grain/time). However, for enhancing the filtering quality, we need to use filter function to impact the threshold of rice, specifically as Figure 2.

These are identify results with the axis moving with velocity $\mathrm{V}=4.8 \mathrm{~m} / \mathrm{s}$. From this result, we can easily identify good rice at high speed.

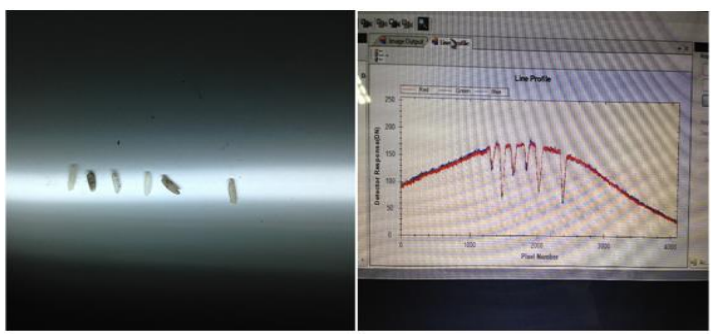

Figure 3. Effect of bad rice through line CCD camera

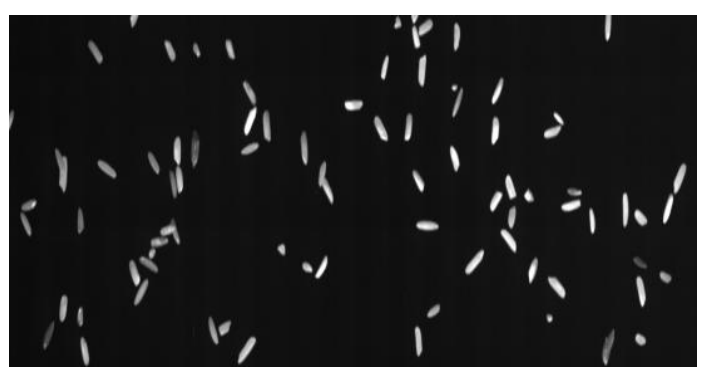

Figure 4. Imagine datas of rice collected at speed 18500 frames/s

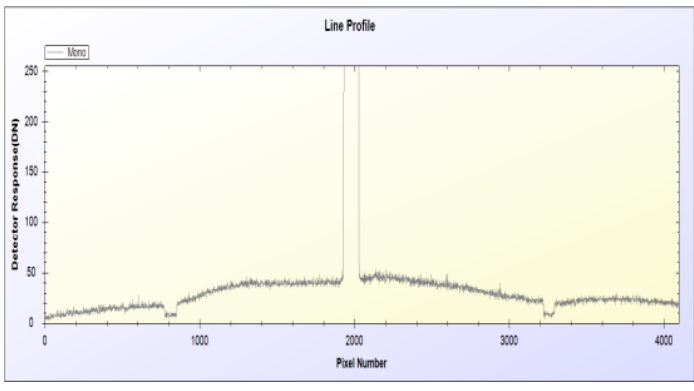

Figure 5. Rice threshold collected when analyzed at high speed 18500 frames/s

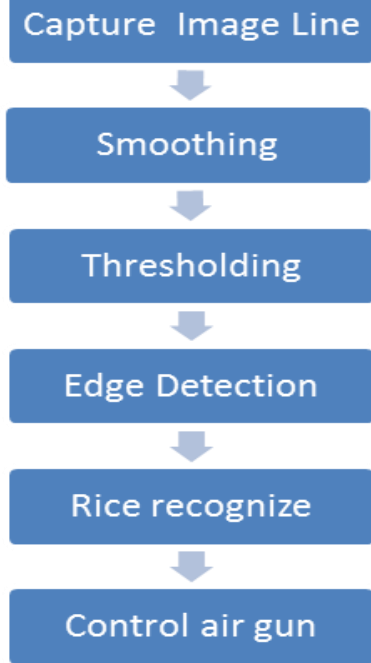

Figure 6. Flow chart of resorting procedure

We have some comments as follows:

If the image capturing speed is higher, the light of system must be stronger too. With $3 \mathrm{~mm}$ x $5 \mathrm{~mm}$ grain-size identification requirement and speed response of valve is $1 \mathrm{~ms}$, we need the scan-time is shorter than $1 \mathrm{~m}$. To determining the minimum requirement speed, we can make some calculation as follows:

- Supposing: rice velocity is $\mathrm{V}=5 \mathrm{~m} / \mathrm{s}$, we need to identify rice by taking $\mathrm{n}$ points on it, and each time taking pictures takes time $\mathrm{t}(1 / \mathrm{f}=$ $1 / 18500=55$ us cycle image capture). So we will build the image of size $\mathrm{n} * \mathrm{v} * \mathrm{t}>3 \mathrm{~mm} \square \mathrm{n}>3 \mathrm{~mm}$ $/(5 \mathrm{~m} / \mathrm{s} * 55 \mathrm{us})=11$ points, we could be easily built 11x11 matrix to perform color processing rice. Thus the higher the frequency will get good quality, but the system must be bright enough.

From the collected data of matrix, we implement to estimate the threshold and use EROSION algorithm to solve high speed identifying. 



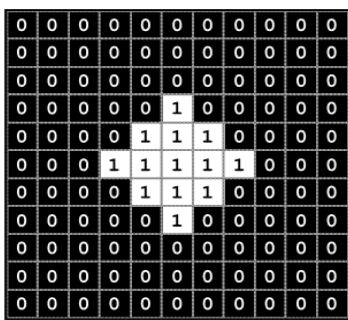

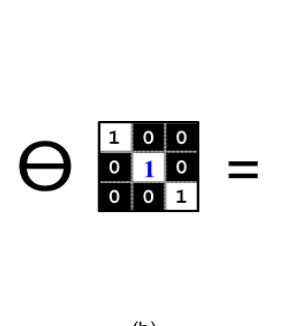

(b)

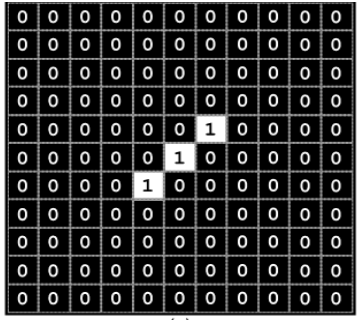

(c)

(b) Structustration of morphological erosion. (a) Original binary image with a diamond object; (b) Structure element with three pixels arranged in a diagonal line at angle of 1350, the origin the structure element is clearly identified by a red 1 ; (c) Eroded image, a value of 1 at each location of the origin of the structure element, such that the element overlaps only 1 -valued pixels of the input image (i.e., it does not overlap any of the image background).

Figure 7. Erosion algorithm

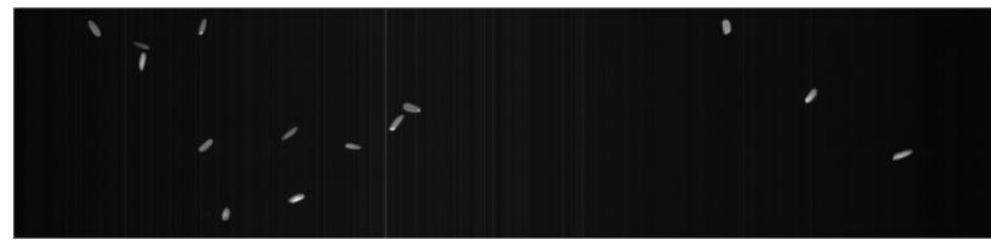

Figure 8-a. Image collected from the camera at $18500 \mathrm{HZ}$ speed and aperture brightness time 55us

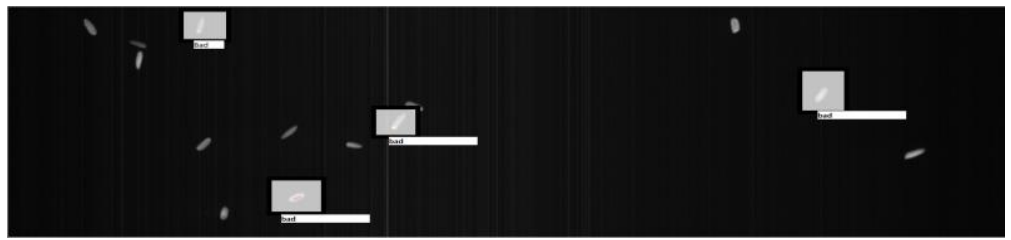

Figure 8-b. Bad rice identified and marked by the algorithm

Identification algorithm easily discovers the bad rice base on the contrast background and minimize color threshold of rice. Algorithm is simple and easy that contribute to speed up image processing $<0.1 \mathrm{~ms}$ (Experimental data process all). The algorithm combines with the wavelength of light so the processing system has no very great error than rice color separation processing.

\section{CONCLUSION}

This paper summarizes a method to identifying bad grain by combining the light wavelength and high frequency filtering threshold. This is a new method for image processing recognition, because up to now. By combining wavelengths in Figure 3, the processing help from threshold (Figure 5) and recognize (Figure 4) is easily done.

In addition, mass processing on matrix helped to easily identify quality of rice (Figure 4). From the data in Figure $4 \& 5$ that help to easily determine bad / good rice (Figure 8-a, 8-b) by applying the basic algorithms such as: threshold filtering for figure. 5, and erosion algorithms for figure. 4.

ACKNOWLEDGMENTS: This research was supported by National Key Laboratory of Digital Control and System Engineering (DCSELAB), HCMUT, VNU-HCM. 
View video at:

1.Synchronization recognize rice \& Valve :
2. Test machine:

https://www.youtube.com/watch?v=CsG0246uNGM

https://www.youtube.com/watch?v=gXxiPjkvJHo\&list

$=\mathrm{UUFS} 8 \mathrm{zFuB} 4 \mathrm{e} 7 \mathrm{Im} 9 \mathrm{zbvXjvfqQ}$

\section{Thuật toán nhận dạng và tách màu gạo}

- Phan Huỳnh Lâm

- Nguyễn Thanh Nam

- Phạm Văn Duy

- Nguyễn Thiên Bình

- Lê Thanh Sơn

DCSELAB, Trường Đại học Bách Khoa, ĐHQG-HCM

TÓM TÁT:

Bài báo trình bày phương pháp nhận dạng ra hạt gạo tốt và xấu để xử lý phân loại. Thuật toán đề cập ở đây sẽ xác định ra hạt gạo tốt và xấu ở tốc độ cao (18500 frame/s), và xác định vận tốc di chuyển của gạo. Việc xác định ra gạo tốt xấu ngoài dùng ngướng mức, trong thuật toán

Tùr khóa: CCD Line, rice sorting, OpenCV.

\section{REFERENCES}

[1]. IT-P1-4096 Linear CCD DALSA

[2]. B. S. Anami, V. Burkpalli, S. A. Angadi, and N. M. Patil, "Neural network approach for grain classification and gradation," Proceedings of the second national conference on document analysis and recognition, pp. 394-408, July 2003.

[3]. N. S. Visen, J. Paliwal, D. S. Jayas, and N. D. G. White, "Image analysis of bulk grain samples using neural networks," Canadian còn kết hợp bước sóng ánh sáng phù hợp và nhận dạng độ dài hạt gạo. Bài báo mô tả kết quả thực nghiệm : ảnh hưởng của bước sóng ánh sáng, ảnh hưởng của tốc độ lấy ảnh, kỹ thuật nhận dạng và ngưỡng lọc.

Biosystems Engineering, vol. 46, pp. 7.117.18, 2004.

[4]. R. M. Haralick, K. Shanmugam, and I. Dinstein, "Texture features for image classification," IEEE Trans. on Syst.,Man, and cybern, vol 6, pp. 610-621, 1973.

[5]. L. Zhao yan, C. Fang, Y. Yibin, and R. Xiuqin, "Identification of rice seed varieties using neural network", Journal of Zhejiang University SCIENCE, September 2005. 
[6]. M. A. Shahin and S. J. Symons, "Seed sizing from images of non-singulated grain samples", Can. BioSyst. Eng, vol. 47, 2005.

[7]. J. Paliwal, M. S. Borhan and D. S. Jayas, "Classification of cereal grain using a flatbed scanner", Can Biosyst Eng, vol. 46, 2004.

[8]. Sanjivani Shantaiya, Mrs.Uzma Ansari, "Identification Of Food Grain And Its Quality Using Pattern Classification,"
International Journal of Computer \& Communication Technology, vol 2, 2010.

[9]. H. Rautio and O. Silvn, "Average Grain Size Determination using Mathematical Morphology and Texture Analysis".

[10]. S. Deena Christilda, M. Prathiba, and P. Neelamegam , " Quality Inspection of Parenteral Vials Using Digital Image Analysis," Sensors \&

[11]. Transducers Journal, Vol. 145, Issue 10, pp. 130-137, October 2012. 